\title{
Renal Calculi (Kidney Stones) and its Therapy
}

\author{
N.K. Mishra* \\ Jeypore College of Pharmacy, Rondapalli, Jeypore, Dist: Koraput, 764002, Odisha, India
}

Address for Correspondence: N.K. Mishra, montu.mph@gmail.com

\section{Received: 13.03.2018 Accepted:} 03.10 .2018

\section{Keywords} Kidney stone; Calcium oxalate; Calcium phosphate uric acid; Ureteroscopy.

\begin{abstract}
Kidney stone is one of the most common problems of the urinary system. The epidemiology in US describe prevalence is $3 \%$ of the all population and it affects up to $12 \%$ of the population during their life time. In 1980, about 3 in every 100 populations developed a stone some points in their life. In 1994 the number rises to 5 in every 100 populations. By 2010, it became almost 9 in 100 populations. The children and adults both are affected in kidney stone. However, males are affected more than females. The risk factors for kidney stones are hypertension, metabolic acidosis, a history of gout arthritis, insulin resistant. The kidney stones are generally due to calcium oxalate, calcium phosphate and uric acid. It can be prevented by dietary control and intake of sufficient amount of water. Recently the Ureteroscopy surgical procedure can able to control 10-20\% of kidney stones and the success rate is also very high. (C) 2019 iGlobal Research and Publishing Foundation. All rights reserved.
\end{abstract}

Cite this article as: Mishra, N.K. Renal calculi (kidney stones) and it's therapy. Indo Global J. Pharm. Sci., 2019; 9(1): 1-4 . DOI: http://doi.org/10.35652/IGJPS.2019.9101 .

\section{INTRODUCTION}

The renal calculi (Kidney stones) are the small heard stones vary in sizes that form in the kidney when the salts in the urine became solid. Some cases the clump of crystals is formed together, which create a hard lump in one or both the kidneys. They can vary in size from a few millimetres to centimetres. Maximum cases they can be present for longer periods without any types of discomfort. But in some cases the stone drops into the ureter (pipe from kidney to bladder); get stuck and causes severe pain. Anybody can get a kidney stone. The clinical reports instruct 1 in 10 men and 1 in 35 women develop a kidney stone in their lifetime. The life time risk of stone formation in an individual is estimated at the level of 510\%. [1, 2] It has been informed that inappropriate dietary habits and lifestyle promote kidney stone formation. The medical reports of kidney stone patient are focused on identifying various abnormalities in urine composition which cause kidney stone. The urine composition can be affected by dietary habits, systemic diseases and environmental factors. The goal of this review is to instruct about the kidney stones, its cause, diagnosis, prevention and therapeutic aspects.

\section{CLASSIFICATION OF KIDNEY STONES}

1. Calcium

Most of the kidney stones are composed of calcium and hypercalciuria is the most common metabolic abnormality found in calcium stone formers. This is due to the wrong mix of chemicals in the urine, which allows salts to turn into crystals. In hypercalciuria, the urine calcium level increases more than $300 \mathrm{mg} / \mathrm{d}$ in case of man and $250 \mathrm{mg} / \mathrm{d}$ in case of women. The calcium level in urine greater than the normal 
Indo Global Journal of Pharmaceutical Sciences, 2019; 9(1):1-4

value may develop to kidney stone. This can be caused by eating too much calcium rich diet (Fig.1: A).

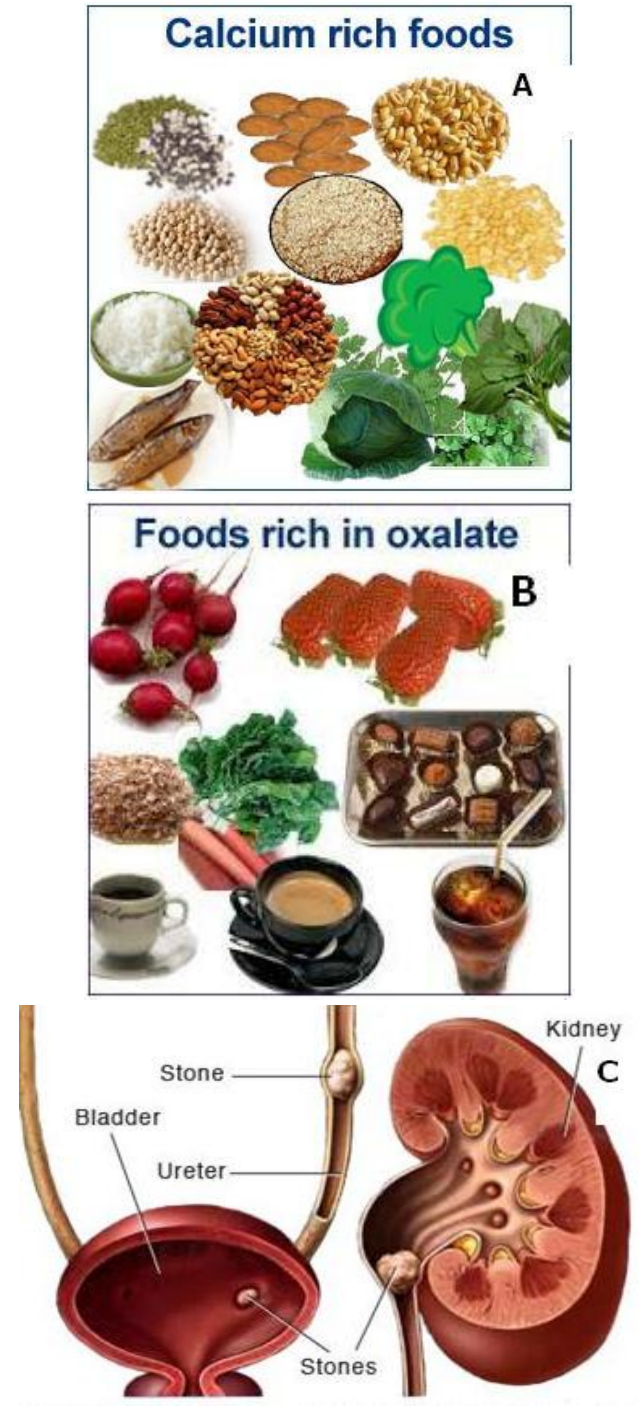

Fig.1: A- Calcium rich diet [16], B- Oxalate rich diet [17], CKidney stone and passing in to the bladder.

\section{Oxalate}

Approximately $30 \%$ of kidney stones are due to hyperoxaluria. This can be caused by eating too many oxalate rich diet (Fig.1B: Spinach, Bran flakes, beets, nuts and nut butters) or intestinal diseases.

\section{Citrates}

Citrate reduces the risk of kidney stone by forming complexion with calcium in the urine. This reduces the free calcium level in urine. [3] In case of hypocitraturia the citrate level is less than $325 \mathrm{mg} / \mathrm{d}$ which facilitate the kidney stone.

\section{Uric acid}

Increase uric acid level in urine (Hyperuricosuria) promotes the stone formation by salting out the calcium oxalate $(\mathrm{CaOx})$ from the urine. [4] Allopurinol has been found to be decreases the uric acid excretion and reduced the $\mathrm{CaOx}$.

Different rates of different types of kidney stones in adults and children (Table 1). [5, 6]

Table 1: Kidney Stone incidence in adults and children

\begin{tabular}{|l|l|l|}
\hline Types of stone & Adult $(\boldsymbol{\%})$ & Children (\%) \\
\hline Calcium oxalate & $56-61$ & $45-65$ \\
\hline Calcium phosphate & $8-18$ & $24-30$ \\
\hline Uric acid & $9-17$ & $2-4$ \\
\hline Other & 2 & 4 \\
\hline
\end{tabular}

\section{RISK FACTORS FOR KIDNEY STONES}

In maximum cases it is very difficult to identify the causative factor. A family history of kidney stones, history of hypertension, metabolic acidosis, a history of gout arthritis, insulin resistant states are all associated with risk of kidney stones. $[5,6]$

\section{CLINICAL SIGNS AND SYMPTOMS}

The patient may feel a strong gripping pain in the back below the ribs and may have pain in the groin and thigh region. The other symptoms may include-

- Pain on urination

- Pink, red or brown urine

- Cloudy or foul-smelling urine

- Blood in urine

- Frequent urination

- Nausea and vomiting

- Sweating, fever and shivers

The pain attack may be several hours. The symptoms may be reduced once the stone passes in to the bladder (Fig.1C). Some cases people don't know when this happens. [7]

\section{EPIDEMIOLOGY OF KIDNEY STONES}

The survey report (Table 2) in United States indicates, the stone prevalence has doubled since 1964-1972 time period and increased in 1982. [8] Similarly in the other countries like Spain, Italy and Turkey the prevalence increases. $[9,10]$ Only in case of Scotland the prevalence is slightly decrease from $3.83 \%$ to $3.5 \%$ in 1977 to 1987 respectively. [11] 
Indo Global Journal of Pharmaceutical Sciences, 2019; 9(1):1-4

Table 2: Reported survey on Kidney stone and prevalence by different countries and Year

\begin{tabular}{|l|l|l|l|}
\hline Country & Year & Population & Prevalence \\
\hline United states & $1964-$ & All & $2.62 \%$ \\
& 1972 & All & $5.4 \%$ \\
& 1982 & All & $5.2 \%$ \\
& $1988-$ & & \\
& 1994 & & \\
\hline Turkey & 1989 & All & $14.8 \%$ \\
\hline Scotland & 1977 & All & $3.83 \%$ \\
& 1987 & All & $3.5 \%$ \\
\hline Italy & 1983 & All & $1.17 \%$ \\
& $1993-$ & All & $1.72 \%$ \\
& 1994 & & \\
\hline Spain & 1977 & All & $0.1 \%$ \\
& 1979 & All & $3.0 \%$ \\
& 1991 & All & $10 \%$ \\
\hline
\end{tabular}

\section{PATHOPHYSIOLOGY}

Recently it was found that the kidney stones are due to nanobacterial diseases particular to Helicobacter pylori infection and peptic ulcer diseases. [12] The bacteria formed intracellular calcium phosphate shell and present in the central nidus of most (97\%) kidney stones and in mineral plague in the renal papilla. Further the crystallization and growth of stones are influenced by endogenous and dietary factors. Crystallization occurs when the concentration of two ions exceeds their saturation point in the solution.

\section{PREVENTION OF COMMON KIDNEY STONES}

\section{Increase fluid in take}

Fluid intake reduces the risk of stone formation. When a person is well hydrated the urine colour will be pale. The pale urine indicates less concentration of waste products of calcium, oxalate and uric acid. A fluid intake to produce a consistent urine volume of at least 21 per day is recommended for the prevention of stone formation. Hence it is advised to drink 2-3 1 of water or enough fluid to produce a urine output of two liters per day. Type of fluid intake is also very much important. Clinically it has been observed that coffee and beer give protection while grape and fruit juice increases the chances of stone. [13]

\section{Controlling adequate salt intake}

High salt (containing sodium chloride) intake leads to increase in the risk of stone formation. It is better to take less than 6grams of salt to avoid kidney stones. The following guide provides the safety consumption of salt in diet (Table 3).
Table 3: Guide line to check salt content in diet

\begin{tabular}{|l|l|l|l|}
\hline & Low & Medium & High \\
\hline $\begin{array}{l}\text { Salt per 100g } \\
\text { diet }\end{array}$ & $\begin{array}{l}\text { Less than } \\
0.3 \mathrm{~g}\end{array}$ & $0.3-1.5 \mathrm{~g}$ & $\begin{array}{l}\text { More than } \\
1.5 \mathrm{~g}\end{array}$ \\
\hline $\begin{array}{l}\text { Sodium (per } \\
\text { 100g) diet }\end{array}$ & $\begin{array}{l}\text { Less than } \\
0.12 \mathrm{~g}\end{array}$ & $0.12-0.6 \mathrm{~g}$ & $\begin{array}{l}\text { More than } \\
0.6 \mathrm{~g}\end{array}$ \\
\hline
\end{tabular}

\section{Controlling adequate calcium intake}

Low level of calcium and high level of calcium results kidney stone. Calcium in diet binds with the oxalate in the gut and prevents absorption of oxalate. Hence low-calcium diets are not recommended because of maximum absorption of oxalate increases urine level and increase the risk of stone formation. However, more than $1200 \mathrm{mg} /$ day may leads to hypercalciuria. In order to maintain healthy calcium level in man and women the following guidelines (Table 4).

Table 4: Guide line to recommend daily amount of calcium

\begin{tabular}{|l|l|l|}
\hline Men & $11-18$ years & $1000 \mathrm{mg}$ \\
\cline { 2 - 3 } & $19+$ years & $700 \mathrm{mg}$ \\
\hline \multirow{3}{*}{ Women } & $11-18$ years & $800 \mathrm{mg}$ \\
\cline { 2 - 3 } & $19+$ years & $700 \mathrm{mg}$ \\
\cline { 2 - 3 } & Brest feeding & $1,250 \mathrm{mg}$ \\
\hline
\end{tabular}

\section{Intake of citric acid}

Citric acid is an organic acid mostly found in many fruits and fruit juice. It is very much beneficial to the people having kidney stone. It inhibits stone formation and breaks up small stones staring to form. Citric acid is protective against stone formation if it is available in the urine adequate amount. The best source of citric acid is lemons while oranges, grape fruits and berries also contain appreciable amounts. A half-cup (4 ounces) of pure lemon juice per day provides the similar amount of citric acid as dose pharmacological therapy.

\section{Prevention of oxalate containing food intake}

It is suggested to avoid to intake foods that are rich source of oxalates (Fig.1B) and should be eaten sparingly. It includes all-barns, almonds, beets, rhubarbs etc.

\section{Maintain healthy body weight}

A healthy weight indicates the body mass index (BMI) between $19-25 \mathrm{~kg} / \mathrm{m} 2$. Obesity is a risk factor for stones. Obesity may change the acid levels in the urine, leading to stone formation.

\section{DIAGNOSIS OF KIDNEY STONE}

Kidney stone can be diagnosis by ultrasound, intravenous pyleography (IVP) or a CT scan. Urologists are increasingly 
Indo Global Journal of Pharmaceutical Sciences, 2019; 9(1):1-4

using Ureteroscopy to remove stones. In this type of diagnosis the calcium oxalate are visible.

\section{TREATMENT OF KIDNEY STONES}

\section{Medication}

Certain medications have been shown to improve the chance that a stone will pass through the urine. The medication used for this purpose is Tamsulosin $\alpha 1$ - blocker relaxes the ureter which helps the stone to pass easily. The other medications include calcium channel blockers, steroids and non-steroidal anti inflammatory drugs (NSAIDS). The steroids are useful to decrease mucosal edema and aid in stone passage. The calcium channel blocker Nifiedipine is used to treat ureteral spasm and promotes stone passage. [14] NSAIDS also have the potential to decrease inflammation and mucosal edema. The diuretic particularly thiazide drugs are also helpful to eliminate the stones by increasing the hydrostatic pressure within the ureter.

\section{Surgical therapy}

The surgical process has been recently reviewed. Surgical therapy is helpful recently to control $10-20 \%$ of kidney stones. Ureteroscopy is most successful for stones larger than $1 \mathrm{~cm}$. In this type of surgical process holmium: yttrium-aluminumgarnet (YAG) laser (photo thermal lithotripsy) is used for stone of all composition and sizes. The success rate of this therapy is $97-100 \%$. [15]

\section{CONCLUSION}

It is better to take preventive measure to control the kidney stones. Since citric acid is protective against stone formation, regular intake may helpful to control it. However the medication and surgical therapy are also able to reduce the kidney stone successfully.

\section{ACKNOWLEDGEMENT}

I am very much grateful to Prof. (Dr.) P. K. Kar; Principal and Prof.(Dr.) Sruti Ranjan Mishra; Director Jeypore College of
Pharmacy, Rondapalli, Jeypore, Dist: Koraput, 764002, Odisha, India for inspiring to write the article.

\section{CONFLICTS OF INTEREST}

Author declares no conflict of interest.

\section{REFERENCES}

1. Pearle, M.S., Calhoun, E.A., Curhan, G.C. Urologic diseases in America project. J of Uro., 2005; 173:848-57.

2. Stamatelou, K.K., Francis, M.E., Jones, C.A., Nyberg, L.M., Curhan, G.C. Time trends in reported prevalence of kidney stones in the United States. Kidney Inter., 2003; 63:1817-23.

3. Nicar, M.J., Hill, K., Pak, C.Y.C. Inhibition by citrate of spontaneous precipitation of calcium oxalate in vitro. $\mathrm{J}$ of Bone and Miner Res., 1987; 2:215-20.

4. Ryall, R., Grover, P., Marshall, V. Urate and calcium stones-picking up a drop of mercury with one's fingers. Amer. J of Kidney Dis., 1991 27: 426-30.

5. Ross, A.E., Handa, S., Lingeman, J.E., Matlaga, B.R. Kidney stones during pregnancy: an investigation into stone composition. Urologica Res., 2008; 36(2): 99-102.

6. Rule, A.D., Bergstralh, E.J., Melton, L.J., Li, X., Weaver, A.L., Lieske, J.C. Kidney stones and the risk for chronic kidney disease. Clin. J. of Americ. Soci. of Nephrolo., 2009; 4(4):804-811.

7. Mattix Kramer, H.J., Grodstein, F., Stampfer, M.J., Curhan, G.C. Menopause and postmenopausal hormone use and risk of incident kidney stones. J of the Americ. Soci. of Nephrolo, 2003; 14:1272-7.

8. Hiatt, R.A., Dales, L.G., Friedman, G.D., Hunkeler, E.M. Frequency of urolithiasis in a prepaid medical care program. Americ. J of Epidemio., 1982; 115:255-265.

9. Sánchez-Martín, F.M. et al. Incidence and prevalence of published studies about urolithiasis in Spain: a review. Actas. Urologi. Espanol., 2007; 31:511-520.

10. Trinchieri, A. et al. Increase in the prevalence of symptomatic urinary tract stones during the last ten years. Euro. Urol., 2000; 37:23-25.

11. Scott, R. et al. The prevalence of calcified upper urinary tract stone disease in a random population-Cumbernauld Health Survey. Brit. J of Urol., 1977; 49:589-595.

12. Ciftcioglu, N., Bjorklund, M., Kuorikoski, K., Bergstrom, K., Kajander, E.O. Nanobacteria: an infectious cause for kidney stone formation. Kidney Int-J., 1999; 56:1893-8.

13. Curhan, G., Willett, W., Speizer, F., Stampfer, M. Beverage use and risk for kidney stones in women. Annal. of Inter. Med., 1998; 128: 534-40.

14. Porpiglia, F., Ghignone, G., Fiori, C., Fontana, D., Scarpa, R. Nifedipine versus tamsulosin for the management of lower ureteral stones. J of Urolo. 2004; 172(2):568-571.

15. Sofer, M., Watterson, J.D., Wollin, T.A., Nott, L., Razvi, H., Denstedt, J.D. Holmium: YAG laser lithotripsy for upper urinary tract calculi in 598 patients. J of Urolo., 2002; 167: 31-4.

16. http://www.google.co.in calcium+rich+food.

17. http://www.google.co.in oxalate+rich+food

Indo Global Journal of Pharmaceutical Sciences( ISSN 2249 1023; CODEN- IGJPAI; NLM ID: 101610675) indexed and abstracted in CrossRef (DOI Enabling), UGC CARE Journal List, EMBASE(Elsevier), National Library of Medicine (NLM) Catalog, ResearchGate, Publons, CAS (ACS), Index Copernicus, Google Scholar and many more. For further details, visit http://iglobaljournal.com 